\title{
Makine Düşünebilir mi ve Nasıl Düşünebilir?
}

\author{
Matematik ve Matematik Mühendisliği Topluluğu ${ }^{1}$ \\ ${ }^{1}$ Affiliation not available
}

December 1, 2020

Yapay zeka ile ilgilenen kişilerin duymuş olabileceğini düşündüğümüz, Cahit Arf'ın makinelerin düşünmesi ile ilgili verdiği bir halk konferansını MMMT olarak inceledik ve bunu yazıya döktük. Ünlü bilim insanı ve matematikçi Cahit Arf'ın hayatını ve bilinmeyen detaylarını işlediğimiz yazıya buraya tıklayarak ulaşabilirsiniz: \#İzBırakanlar 001: Matematiğin Arf Halkası Cahit Arf

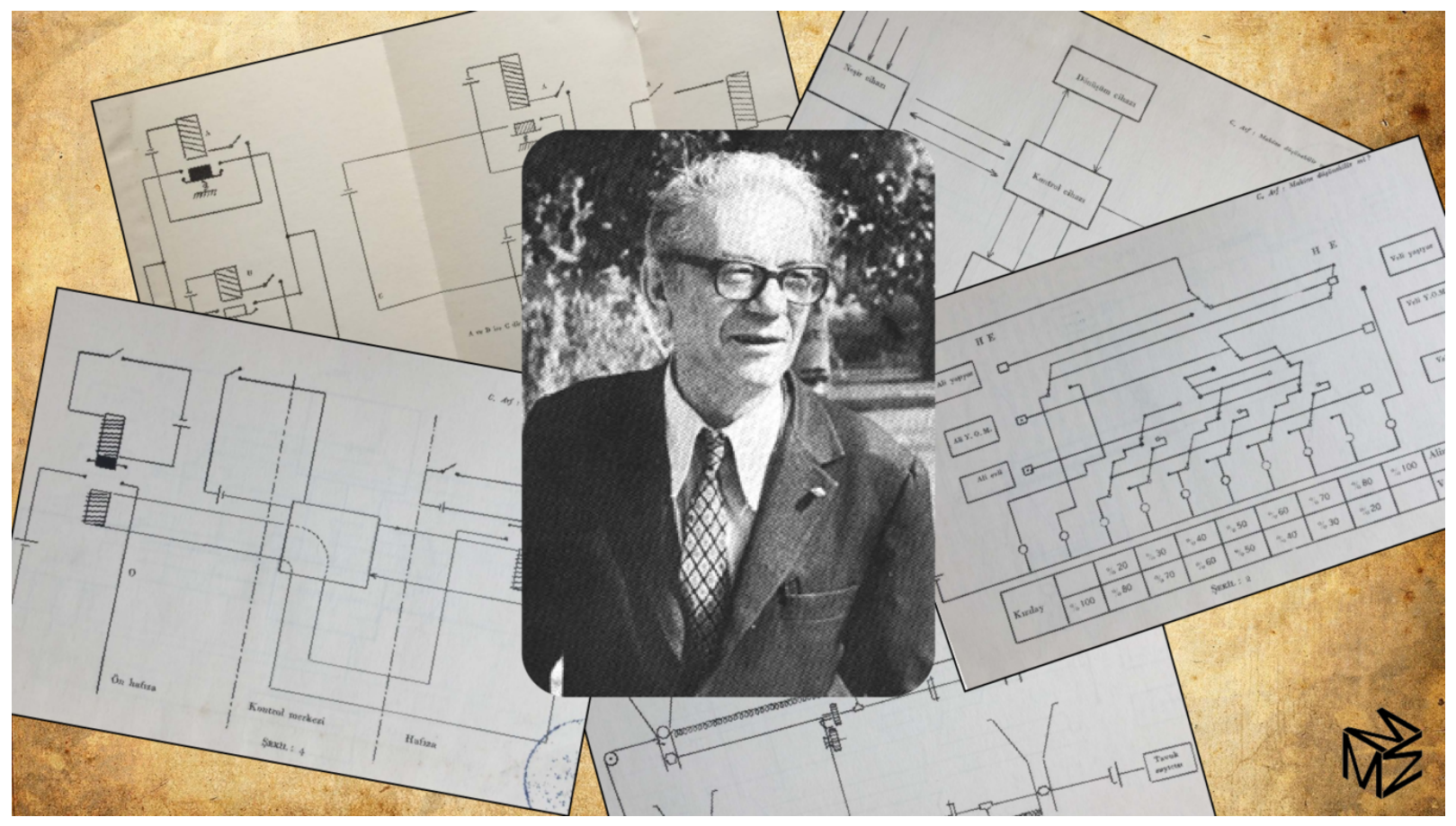

Cahit Arf, 1959 senesinde Erzurum Atatürk Üniversitesi'nde "Makine düşünebilir mi ve Nasıl Düşünebilir?" başlığı altında bir konferans vermiştir. Konferansta iletişimin girdilere ve çıktılara göre anlamlı hale gelmesine birçok örnekte bulunmuş ve basit bir dil ile anlatım yapmıştır. Örneğin çalar saate girdi olarak saat dörtte çalması için ayarlama yaptığımızda, vakti geldiğinde bize saatin dört olduğunu bildirmek üzere bir çıktı olarak zili ile ses çıkartması ve bizim de uyanıp saatin verdiği çıktıyı anlayıp cevap olarak kapatmamız durumunu anlatmıştır ve çeşitlendirmiştir.

Bir kümeste bulunan tavuk ve tavşanların toplam baş ve ayak sayısı verilerek kümeste kaç tavşan ve kaç tavuk olduğu sorusunu çözen bir mekanik hesaplama makinesini anlatmıştır. Akabinde bir mirasta pay bölümünde, verilen girdiye göre hisse paylaşımına karar veren bir sistemi elektronik olarak çalışacak bir şema üzerinden anlatmıştır. Bu, aklımıza 1946 senesinde ilk programlanabilir genel amaçlı elektronik dijital 
bilgisayar olarak kabul edilen ENIAC'ı getiriyor. Ek olarak ENIGMA'dan gelen bilgileri deşifre ederek II. Dünya Savaşı'nın seyrini değiştiren Alan Turing'in tasarladığı Bombe Makinesi'ni de hatırlayalım.

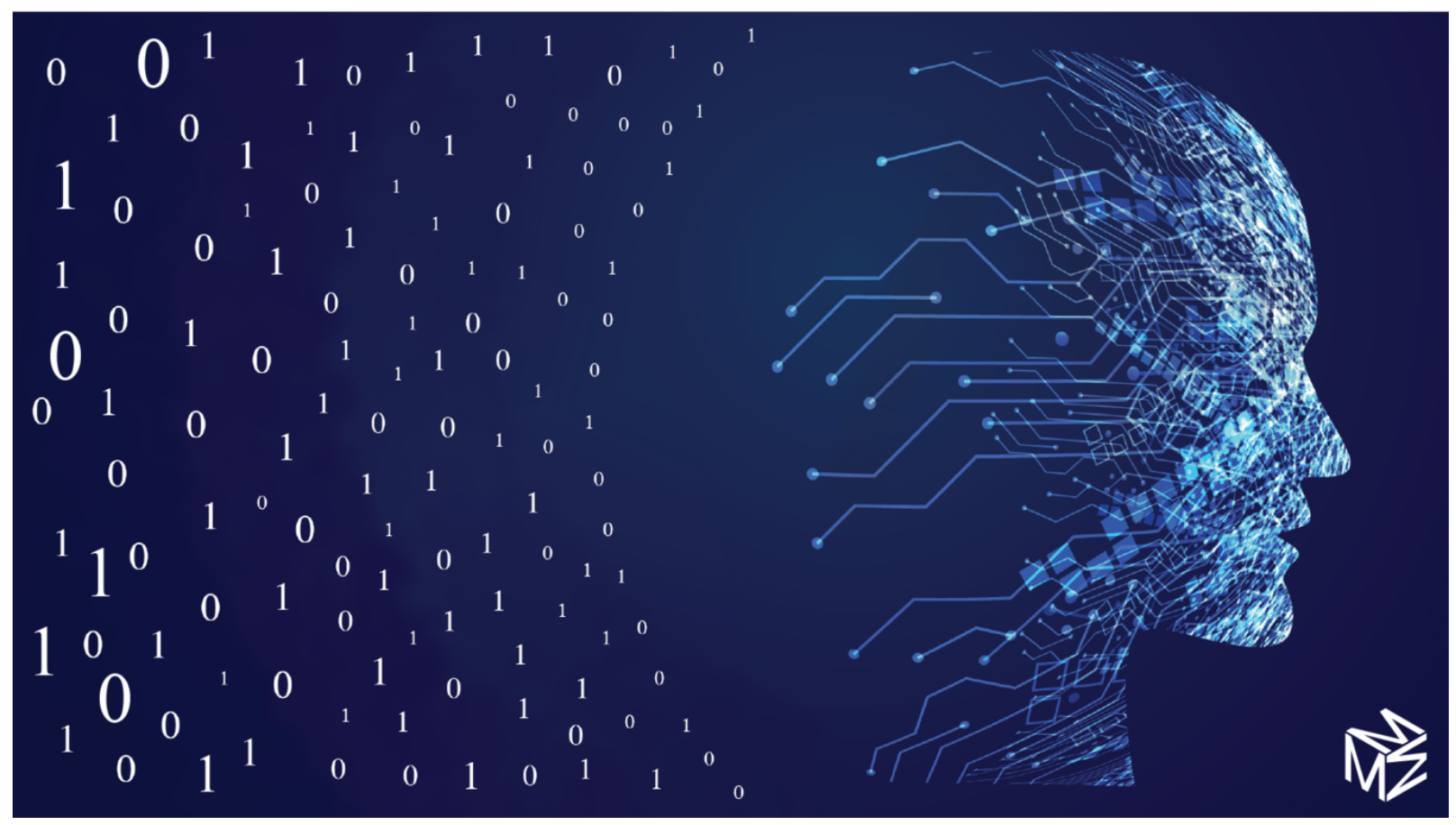

Arf, yukarıda verilen iki işi yapan makine örneklerinin yalnızca makineyi yaparken çözdüğümüz problemleri çözebilen değil, düşünülmemiş olan problemleri de çözebilen bir makine yapılabilir mi sorusunu sormuştur. Bu soruya açıklık getirme adına beynin çalışma sistemi ile benzer bir şema oluşturmuş ve bunu makinelere benzetmiş, iletişim kurarken kullandığımız cümlelerin en küçük yapı taşı olan harfleri bir bilgisayarın anlayabilmesi için ikili sisteme indirgemiş ve alfabemizi 5 bitlik bir sisteme oturtarak örneklendirmiştir. (Alfabemizde 29 harf vardır. 5 bitlik bir dijital sistem $2^{5}=32$ farklı değeri tutmamızı sağlar. Ki bu, alfabedeki harfler için yeterlidir.) Örneğin $\mathrm{M}=01100 . \quad 0$ ve 1 durumlarını elektrik devresinde mıknatıslı röleler ile anlatmış ve elektrik geçip geçmemesine göre mantık (logic) çerçevesinde bu sistemi açıklamıştır. 


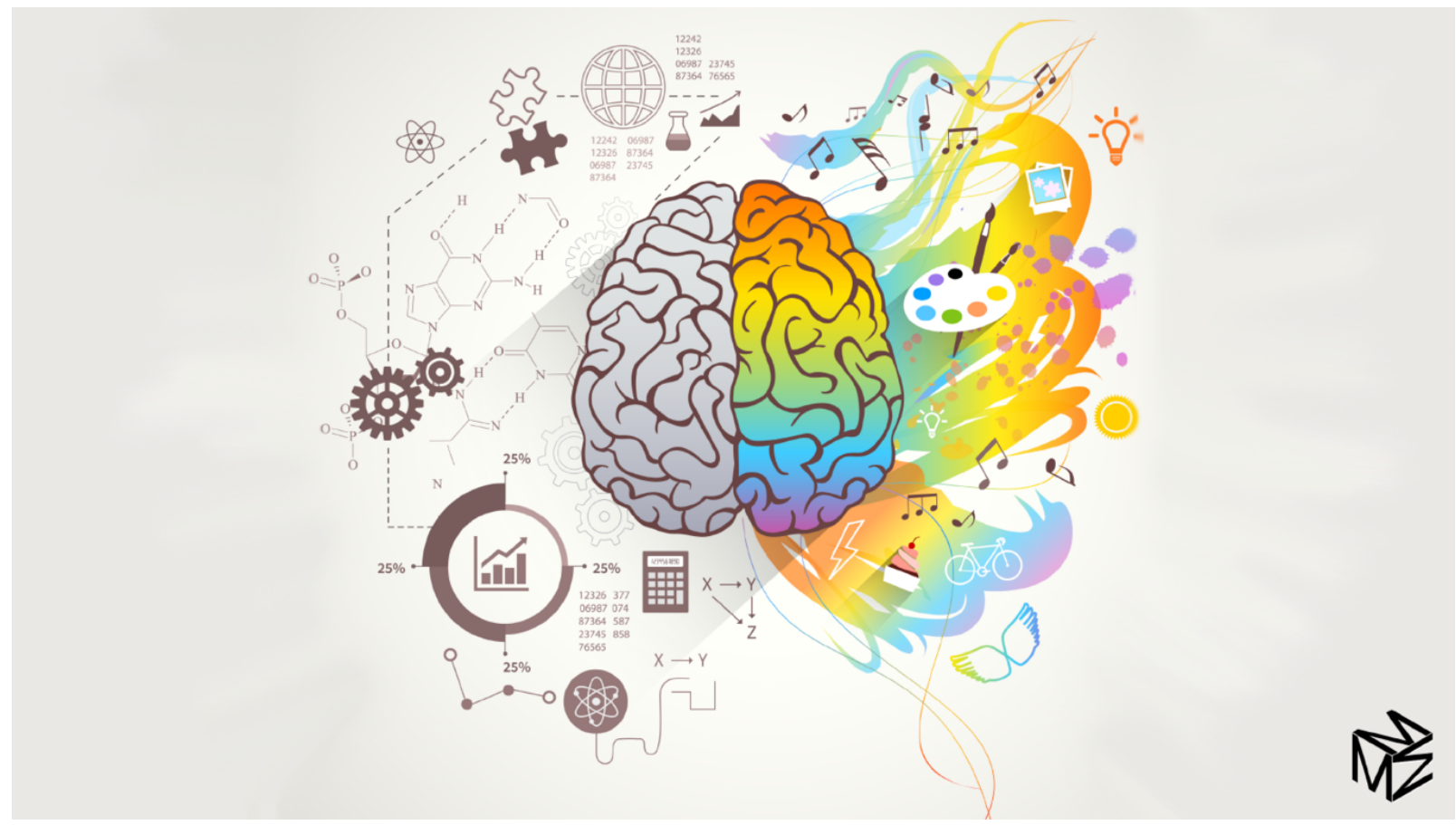

Tüm bu anlatımlarından sonra, bu makinelerin yapabildiklerinin çeşitliliği açısından insan beyninden çok az olduğunu söylemiştir. Ancak asıl farkın, insan beyninin estetik olarak etkenleri alıp onları işlemesi ve estetik olarak kararlar vermesi, bir işi yapıp yapmama konusunda kendini serbest hissetmesine rağmen makinelerde bu tür durumların olmayışı olduğunu söylemiştir. Ve Arf eklemiştir: "Makinelerin estetik bakımdan da insan beynine benzetilecegi umit edilebilecektir. Boyle bir makine, mesela filan muzik parcasını guzel bulmadıgını soyleyebilecektir. Fakat bu isin uzun yuzyıllar sonra bile ve belki de hicbir zaman yapılamayacagını zannediyorum."

Cahit Arf ve konferansı ile ilgili yorumlarınızı sosyal medya hesaplarımızdan bizlerle paylaşmayı unutmayın!

Instagram:@mmmt_digital

LinkedIn: @mmmt-digital

Twitter: @mmmt_digital

Cahit Arf'ın hayatının bilinmeyen detaylarını işlediğimiz yazıya ulaşmak için tıkla: \#їBırakanlar 001: Matematiğin Arf Halkası Cahit Arf

Yazımıza atıfta bulunmak için aşağıdaki gibi APA formatını kullanabilirsiniz:

MMMT. (2020, Kasım 27). Makine Düşünebilir mi ve Nasıl Düşünebilir?. -erişim tarihi- tarihinde, www.authorea.com/495535/cVPtHwGXdl3eSYgkck16uA

adresinden erişildi. 


\section{Referanslar}

[1] Arf, C. (1959). Atatürk Üniversitesi - Üniversite Çalışmalarını Muhite Yayma ve Halk Eğitimi Yayınları Konferanslar Serisi No: 1: Makine Düşünebilir mi ve Nasıl Düşünebilir? 13 Eylül 2020

tarihinde, https://www.mbkaya.com/hukuk/cahit-arf-makine-dusunebilir-mi-orjinal.pdf adresinden erişildi.

[2] Britannica. (2020, Mayıs 27). ENIAC: computer. 2 Eylül 2020 tarihinde, https://www.britannica.com/technology/ENIAC adresinden erişildi.

[3] Britannica. (2019, Haziran 19). Alan Turing: British mathematician and logician. 6 Eylül 2020 tarihinde, https://www.britannica.com/biography/Alan-Turing adresinden erişildi. 